\title{
The influence on birthweight of maternal living conditions a decade prior to giving birth
}

\author{
John Singhammer ${ }^{\mathrm{a}}$, Maurice B. Mittelmark ${ }^{\mathrm{a}}$, Anne-Kjersti Daltveit ${ }^{\mathrm{b}, \mathrm{c}}$ and Grethe S. Tell ${ }^{\mathrm{b}}$ \\ a) Research Centre for Health Promotion, University of Bergen \\ b) Department of Public Health and Primary Health Care, University of Bergen \\ c) Medical Birth Registry of Norway \\ Correspondence: John Singhammer, University of Bergen, Research Centre for Health Promotion, University of Bergen, Norway \\ Telephone: +47 55588988 E-mail: John.Singhammer@psyhp.uib.no
}

\begin{abstract}
The study's aim was to correlate measures of mothers' socio-economic status, a decade prior to giving birth, with their children's birthweight. As part of a larger study, information on birth characteristics from 706 babies born 1970-73 were linked with census data obtained from their mothers near the time of birth as well as one decade earlier. The 706 individuals were selected at random from two national surveys in 1998 and 2000 and traced back to the time of birth in the period 1970-73. Information on birth characteristics was linked to census data obtained from the mothers in 1960 and 1970. Included was information on parent's living conditions (e.g. income, type of dwelling, indoor plumbing, telephone, number of people in the household). Information on mother's health during pregnancy, a decade before childbirth and near childbirth, and data on mothers' and the infants' health at birth was obtained from the Medical Birth Registry of Norway. In analysis that included both early and current socio-economic conditions maternal education and rural residency at the time of giving birth were observed as statistical significant predictors of birthweight. Results were adjusted for maternal age, parity, plurality, gender and diagnoses before and during pregnancy, all factors observed to attenuate birthweight. Indicators of women's socio-economic conditions a decade prior to giving birth were not significantly associated with birthweight. These findings do not clearly support suggestions in the literature that an infant's vitality may be influenced by the family's socio-economic conditions years before birth.
\end{abstract}

\section{BACKGROUND}

The association between parental socio-economic conditions and the health of their offspring is ubiquitous in the scientific literature $(1,2)$. Low birthweight offspring are more frequently observed among women with low education (3-5), among children of labourers (6) and in deprived areas (7). Lower socio-economic status is a risk factor for preterm delivery (8), for having an infant born small for gestational age (9), and for sudden infant death (10). Such associations persist even after accounting for factors such as parity (10), gestational age (11), maternal weight gain (11), maternal disease during pregnancy (12), smoking (8), and alcohol use (13).

Most studies on this topic have measured parental socio-economic status at or near the time of birth (2), and limited number of indicators of socio-economic status have usually been available $(11,14)$. However, theoretical and empirical literature suggests that infant vitality may be influenced by socio-economic conditions years before birth (15-17). This raises the hypothesis that socio-economic conditions measured at the time of birth reflect risk that was present long before conception of the child.

The socio-economic measures that are often used in studies investigating the influence of parental early life socio-economic conditions on infant vitality are education level and occupation. Some other factors that might impart risk may be income, housing quality and general living conditions. A methodological improvement would be to include a comprehensive range of social risk factors measured at several points in time. This would allow a thorough examination of possible effects of different social risk factors beyond what can be captured by including only a single measure of social conditions.
AIMS
The aim of the present study was to correlate measures of mothers' earlier life socio-economic status with their children's birthweight, controlling for other vari- ables known to influence birthweight. Data on birth characteristics obtained from the Medical Birth Regi- stry of Norway were linked to Census data in which the mothers-to-be had participated 10 to 13 years prior to giving birth. This permitted the construction of a unique data set with information on: (1) women's living conditions a decade prior to giving birth; (2) their socio-economic status at time of childbirth; (3) the birthweight of their children, and (4) biomedical factors before and during pregnancy, and at childbirth. 


\section{METHODS}

\section{Study Design}

All Norwegian adults aged 25 to 30 who participated in two national surveys on living conditions conducted in 1998 and 2000, were traced back to the time of birth between 1970 to 1973 . Information on antenatal conditions and birth characteristics was obtained from the Medical Birth Registry of Norway (MBRN), including their mothers' personal identification numbers. This number was then used to trace information the mothers had provided during the census of 1960 and of 1970 . Finally, information on the mothers' highest level of education as of 1970 was obtained from a national education register. This study focuses on the influence of mothers' socio-economic indicators on the weight of their offspring, thus data from 1998 and 2000 are not used here. The study sample consisted of 706 cases born between 1970 and 1973. The MBRN was established in 1967, and that is why index cases were restricted initially to persons aged 25 to 33 . That is, participants in the 1998 and 2000 surveys born too early to appear in the MBRN were not part of the study. Also, index cases born before 1970 were excluded from this analysis because they were born prior to their mother's participation in the 1970 census. Information of the sample selection is provided in figure 1.

\section{The Medical Birth Registry of Norway}

The Medical Birth Registry of Norway (MBRN) has routinely recorded all live and stillbirths (after 16 weeks gestation) in Norway since 1967 (18). All births are reported by midwifes and general practitioners on a standard schedule and send to the MBRN for inclusion in the national registry.

The MBRN includes information on birthweight, length, gestational age in weeks, maternal age, parity, plurality, birth complications, induction procedures, and pathological conditions concerning the placentalutero complex. The registry contains information, also, on mothers' self-reported medical diagnoses before and during pregnancy, including infections, metabolic, cardiovascular, renal and neurological diseases. Diagnoses were classified according to the International Classification of Diseases (ICD-8) during the period of the present study.

For the present analysis, birthweight, the outcome variable, was treated as a continuous measure, and for some analyses was dichotomised into low birthweight $(<2500$ grams $)$ and normal birthweight $(\geq 2500$ grams) (19). Variables that have been observed to attenuate the influence of socio-economic conditions (1), were also included. These were maternal age at delivery, gender of offspring, plurality, parity and selfreported diagnoses before and during pregnancy. Selfreported medical diagnoses prior to and during pregnancy were dichotomised into none versus one or more.

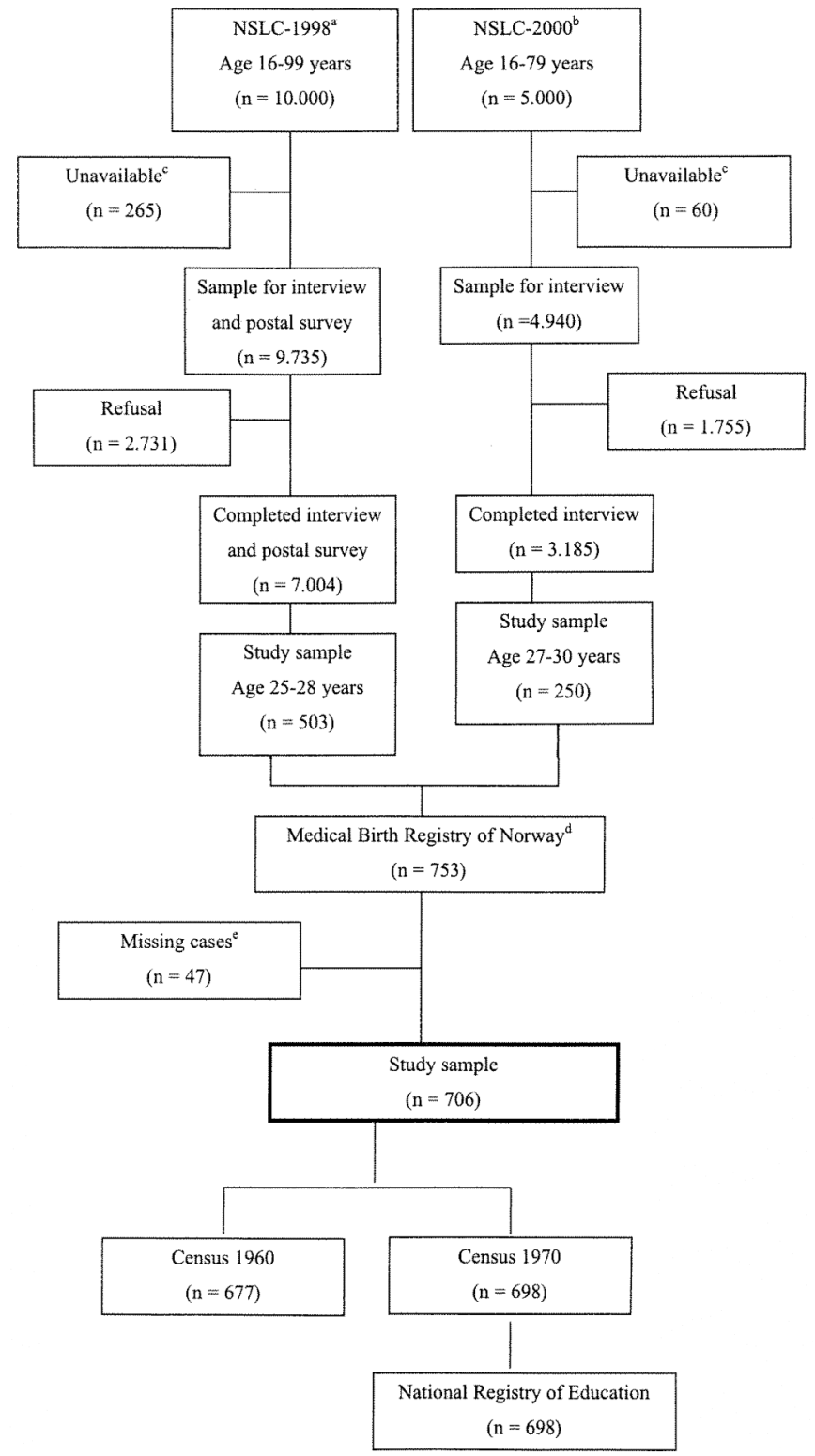

Figure 1. Sample selection.

${ }^{\text {a }}$ National Survey of Living Conditions, 1998

${ }^{\mathrm{b}}$ National Survey of Living Conditions, 2000

${ }^{\mathrm{c}}$ Deceased, institutionalised or emigrated

${ }^{\mathrm{d}}$ Confined to cases born between 1970 and 1973

${ }^{\mathrm{e}}$ Missing cases and cases with a gestational age of 44 week and more were omitted

\section{Census 1960 and 1970}

Census data from 1960 and 1970 represent the mother's socio-economic conditions 10-13 years and 0-3 years respectively, prior to the birth of the study population. At both census, an interviewer visited each individual registered in the National Person Registry of Norway. The head of the household provided information about their age, marital status, place of birth, religion, education, occupational and socio-economic status of all persons in the family and in the household. A family was defined as married couples with or with- 
out children, single parents or single persons living alone. A household was defined as a unit where all families were living under the same roof. Information indicating material wealth such as type of dwelling (self-owned freestanding house, rented apartment et cetera), access to running water, telephone, and indoor toilet were also included, as were neighbourhood density. For these variables, the 1960 and 1970 data were comparable. The measures indicating material wealth (type of dwelling, access to running water, telephone, and indoor toilet) were collapsed into a composite measure for 1960 and 1970, respectively.

Neighbourhood density was dichotomised as urban or rural, with urban defined as areas where more than 200 persons lived in a geographically defined area with less than 50 meters between houses. All other areas were classified as rural. Air photography was used to verify classification in case of uncertainty (20).

Measures of household density were calculated for 1960 and 1970 by dividing the number of persons by the number of rooms in the household (kitchen not included). The scores were dichotomised using the median values as cut-points. A score less than 1.4 defined low density for the measure obtained in 1960, representing the median value. A score of 1.00 or less defined low density for the measure obtained in 1970, also representing the median value.

\section{Methods of analysis}

In the first multivariate analysis birthweight was the predicted variable. Linear multiple regression analysis was used to assess the influence of early socioeconomic conditions in 1960 on subsequent birthweight of the offspring born some 10-13 years later.
The second analysis assessed the influence of early socio-economic conditions on offspring's birthweight, after controlling for socio-economic conditions obtained at about the time of birth. The multivariate analyses were conducted by means of a taxonomy of linear multiple regression models, in which variables were entered in three blocks: (1) socio-economic conditions at the time of birth; (2) the socio-economic conditions of the mothers earlier in life, and; (3) biomedical factors known to be predictors of birthweight. For all regression analysis, variables that did not significantly predict the variance of the outcome of interest were omitted in subsequent models.

Statistical significance was based on two-sided pvalues. A p-value less than 0.05 was considered statistically significant. All analyses were performed using the Statistical Package for the Social Sciences (SPSS version 11.0).

\section{RESUlts}

The distributions of the biomedical variables are displayed in Table 1, and the distributions of the socioeconomic conditions assessed in 1960 and in 1970 are shown in Tables 2 and 3, respectively.

The mean age of mothers-to-be in 1960 was 14.4 years (SD 5.3). 88.8\% of the women were unmarried and of these, $84.2 \%$ reported their parent's income as the main source of living. Maternal age at delivery between 1970 and 1973 ranged from 16 to 45 years. A total of $13.5 \%$ of the sample was 20 years or younger at the time of giving birth, and $7.6 \%$ of the women were either unmarried or divorced. For the 706 births included in this study, induction procedures were

Table 1. Mean birthweight and proportion low birthweight by biomedical factors $(\mathrm{n}=706)$.

\begin{tabular}{lrcc}
\hline $\begin{array}{l}\text { Variables } \\
\text { Gender }\end{array}$ & $\mathrm{N}$ & $\begin{array}{c}\text { Mean birthweight } \\
\text { in grams (SD) }\end{array}$ & $\begin{array}{c}\text { Proportion } \\
<2500 \text { grams (\%) }\end{array}$ \\
$\quad$ Male & 351 & $3630(532)$ & 2.6 \\
$\quad$ Female & 355 & $3408(536)^{* \mathrm{a}}$ & 5.1 \\
$\begin{array}{l}\text { Plurality } \\
\quad \text { Single born }\end{array}$ & 695 & $3531(534)$ & 3.2 \\
$\quad$ Twin & 11 & $2716(593)^{*}$ & $27.3^{* \mathrm{~b}}$ \\
$\begin{array}{l}\text { Parity } \\
\quad \text { Nulliparae }\end{array}$ & & & \\
$\quad$ Multiparae & 299 & $3419(515)$ & 4.3 \\
Diagnoses prior to pregnancy & 404 & $3590(556)^{*}$ & 3.5 \\
$\quad \begin{array}{l}\text { No diagnoses } \\
\quad \text { One or more }\end{array}$ & 643 & $3529(539)$ & 3.3 \\
Diagnoses during pregnancy & 63 & $3413(599)$ & $9.5^{*}$ \\
$\quad$ No diagnoses & & & 2.9 \\
$\quad$ One or more & 620 & $3556(525)$ & $10.5^{*}$ \\
\hline
\end{tabular}

$*^{\mathrm{a}} \mathrm{p}<0.05$ based on two independent sample t-test

${ }^{*} \mathrm{~b} p<0.05$ based on Pearson chi-square test 
Table 2. Mean birthweight and proportion low birthweight by socio-economic indicators in 1960 , about ten years before the birth $(n=706)$.

\begin{tabular}{|c|c|c|c|}
\hline Variables & $\mathrm{N}^{\mathrm{d}}$ & $\begin{array}{l}\text { Mean birthweight } \\
\text { in grams (SD) }\end{array}$ & $\begin{array}{c}\text { Proportion } \\
<2500 \text { grams }(\%)\end{array}$ \\
\hline \multicolumn{4}{|c|}{ Neighbourhood density $1960^{a}$} \\
\hline Urban & 340 & $3487(586)$ & 4.7 \\
\hline Rural & 337 & 3559 (499) & 2.7 \\
\hline \multicolumn{4}{|c|}{ Household density $1960^{b}$} \\
\hline 1.4 or more & 302 & $3482(563)$ & 4.3 \\
\hline$<1.4$ & 371 & 3557 (529) & 3.2 \\
\hline \multicolumn{4}{|c|}{ Material wealth $1960^{c}$} \\
\hline No amenities & 115 & $3462(615)$ & 5.2 \\
\hline One & 185 & $3537(550)$ & 5.4 \\
\hline Two & 184 & $3443(520)$ & 3.8 \\
\hline Three or more & 222 & $3595(514)^{*}$ & 1.8 \\
\hline
\end{tabular}

${ }^{a}$ Neighbourhood density defined by more than 50 meter between the houses and less than 200 person living within a geographically defined area.

${ }^{\mathbf{b}}$ Number of persons in the household divided by the number of rooms in the household.

${ }^{\mathrm{c}}$ A composite score consisting of the variables: type of dwelling, access to running water, telephone, and indoor toilet

${ }^{\mathrm{d}}$ Numbers may differ because of missing values

* $\mathrm{p}<0.05$ based on two independent sample t-test (no differences observed)

Table 3. Birthweight and proportion ${ }^{* b} \mathrm{p}<0.05$ based on Pearson chi-square low birthweight by maternal education, husbands' income, neighbourhood density, household density, and material conditions in 1970 , around the time of birth $(\mathrm{n}=706)$.

\begin{tabular}{|c|c|c|c|}
\hline Variables & $\mathrm{N}^{\mathrm{d}}$ & $\begin{array}{l}\text { Mean birthweight } \\
\text { in grams (SD) }\end{array}$ & $\begin{array}{c}\text { Proportion } \\
<2500 \text { grams }(\%)\end{array}$ \\
\hline \multicolumn{4}{|c|}{ Maternal education } \\
\hline 7 years & 83 & $3369(673)^{*}$ & $9.6^{\dagger}$ \\
\hline 8 years & 130 & $3429(522)$ & 5.4 \\
\hline 9 years & 226 & $3573(574)$ & 4.0 \\
\hline 10 years & 130 & $3541(423)$ & 0.8 \\
\hline 11 years & 137 & $3583(511)$ & 1.5 \\
\hline \multicolumn{4}{|l|}{ Husbands' income } \\
\hline Lowest quintile & 220 & $3450(521)^{*}$ & 4.5 \\
\hline 2 & 128 & $3577(502)$ & 1.6 \\
\hline 3 & 118 & $3501(574)$ & 5.1 \\
\hline 4 & 127 & $3560(543)$ & 2.4 \\
\hline Highest quintile & 105 & $3557(616)$ & 5.7 \\
\hline \multicolumn{4}{|c|}{ Neighbourhood density ${ }^{a}$} \\
\hline Urban & 472 & $3477(562)$ & 4.4 \\
\hline Rural & 226 & $3602(505)$ & 2.7 \\
\hline \multicolumn{4}{|l|}{ Household density $^{b}$} \\
\hline 1.1 or more & 304 & $3508(540)$ & 4.3 \\
\hline$\leq 1.0$ & 392 & $3531(544)$ & 3.3 \\
\hline \multicolumn{4}{|c|}{ Material wealth $1970^{c}$} \\
\hline No amenities & 115 & $3526(501)$ & 2.8 \\
\hline One & 185 & $3620(521)$ & 1.2 \\
\hline Two & 184 & $3466(558)$ & 5.2 \\
\hline Three or more & 222 & $3522(545)$ & 4.0 \\
\hline \multicolumn{4}{|c|}{$\begin{array}{l}\text { Neighbourhood density defined by more than } 50 \text { meter between the houses and less than } 200 \\
\text { persons living within a geographically defined area }\end{array}$} \\
\hline \multicolumn{4}{|c|}{${ }^{b}$ Number of persons in the household divided by the number of rooms in the household } \\
\hline \multicolumn{4}{|c|}{$\begin{array}{l}\text { A composite score consisting of the variables: type of dwelling, access to running water, } \\
\text { telephone, and indoor toilet }\end{array}$} \\
\hline \multicolumn{4}{|c|}{${ }^{\mathrm{d}}$ Numbers may differ because of missing values } \\
\hline \multicolumn{4}{|c|}{ * $p<0.05$ based on analysis of variance (ANOVA) } \\
\hline${ }^{+} \mathrm{p}<0.05$ based on $\mathrm{Pe}$ & & & \\
\hline
\end{tabular}


performed for $12.6 \%$ of all deliveries. The Caesarean section rate was $1.6 \%$. The corresponding figures for the total number of births $(n=259,427)$ during the study period were $12.6 \%$ and $2.5 \%$, respectively.

The measures of material wealth assessed in 1960 and 1970 , respectively ranged from zero to four, with zero indicating no amenities. As the proportion of offspring born with a low birthweight $(<2500$ grams) among mothers with four amenities was too low to yield meaningful results in multivariate analysis it was decided to collapse category three and four of the wealth variables. Cronbach's alpha was 0.50 for the measure of material wealth in 1960 and 0.59 for material wealth in 1970 .

\section{Regression analyses}

In model I, the statistically significant predictors of birthweight were neighbourhood density. Mothers that grew up in rural area in 1960 had offspring that were approximately 90 grams heavier, compared to mothers that grew up in an urban area. The results are shown in Table 4. In model II, the statistically significant attained socio-economic status variables were maternal education, husband's income and rural residence in 1970. Each additional year of maternal education increased the birthweight of the offspring with approximately 67 grams. The final model (III) included the biomedical variables. The statistically significant predictors of birthweight were plurality, gender, parity and diagnoses during pregnancy. The statistically significant effect of husband's income observed in the previous model faded to insignificance. However, maternal education and rural residency remained statistically significant predictors of the offspring's birthweight. Results were adjusted for age at delivery in the final model.

The fact that the age range of the mothers-to-be in 1960 was between 3 and 35 years made us consider possible confounding factors such as age and marriage (and therefore the women were most likely not living by the parents), and own income. Consequently, the multiple regression analysis was also conducted with samples restricted to; (1) women unmarried in 1960 $(\mathrm{n}=627)$; (2) women aged 20 years or less $(\mathrm{n}=577)$, and; (3) women without an income in $1960(\mathrm{n}=566)$. The results of the analyses reported here were basically unaltered.

Table 4. Unstandardised coefficients and standard errors (SE) of multiple regression analyses with birthweight (grams) as dependent variable $(\mathrm{n}=663)$.

\begin{tabular}{|c|c|c|c|c|c|c|}
\hline & \multicolumn{2}{|c|}{ Model I $^{\mathrm{a}}$} & \multicolumn{2}{|c|}{ Model II $^{\mathrm{b}}$} & \multicolumn{2}{|c|}{ Model III $^{\mathrm{c}}$} \\
\hline & B & SE & B & SE & $\mathrm{B}$ & SE \\
\hline \multicolumn{7}{|l|}{ Early socio-economic conditions } \\
\hline Neighbourhood density (urban/rural) & $90.4 *$ & 42.9 & 60.9 & 46.7 & - & - \\
\hline Household density $(1.4$ or more $/<1.4)$ & -55.5 & 44.3 & - & - & - & - \\
\hline Material wealth 1960 (four categories) & 33.3 & 21.0 & - & - & - & - \\
\hline \multicolumn{7}{|l|}{ Attained socio-economic conditions } \\
\hline Maternal education (years) & & & $67.2 *$ & 17.2 & $74.2 *$ & 15.7 \\
\hline Husband's income (quintiles) & & & $33.3^{*}$ & 14.4 & 10.3 & 15.4 \\
\hline Neighbourhood density (urban/rural) & & & $142.3^{*}$ & 49.4 & $121.5^{*}$ & 42.6 \\
\hline Household density $(1.1$ or $\mathrm{more} / \leq 1.0)$ & & & 1.02 & 43.0 & - & - \\
\hline Material wealth 1970 (four categories) & & & -12.5 & 19.5 & - & - \\
\hline \multicolumn{7}{|l|}{ Biomedical variables } \\
\hline Maternal age at delivery (years) & & & & & -34.6 & 20.9 \\
\hline Plurality (twins/single) & & & & & $-776.9^{*}$ & 154.8 \\
\hline Female & & & & & $-201.3^{*}$ & 38.4 \\
\hline Parity (First, second and third born or more) & & & & & $116.8^{*}$ & 29.7 \\
\hline Diagnoses prior to pregnancy (none/one or more) & & & & & 2.4 & 69.8 \\
\hline Diagnoses during pregnancy (none/one or more) & & & & & $-271.2 *$ & 60.7 \\
\hline Adjusted $\mathrm{R}^{2}$ & & & & & & 0.14 \\
\hline \multicolumn{7}{|l|}{${ }^{*} \mathrm{p}<0.05$} \\
\hline \multirow{2}{*}{\multicolumn{7}{|c|}{$\begin{array}{l}\text { a (variables included in Model I: Neighbourhood density 1960, Household density 1960, and Material wealth 1960) } \\
\text { b (variables included in Model II: Neighbourhood density 1960, Maternal education 1970, Husband's education 1970, } \\
\text { Household density 1970, and Material wealth 1970) }\end{array}$}} \\
\hline & & & & & & \\
\hline \multicolumn{7}{|c|}{$\begin{array}{l}\text { ' (variables included in Model III: Maternal education 1970, Husbond's education 1970, Household density 1970, } \\
\text { Maternal age at delivery, Plurality, Female gender, Parity, Diagnoses Prior to Pregnancy, and Diagnoses during } \\
\text { pregnancy) }\end{array}$} \\
\hline
\end{tabular}




\section{DISCUSSION}

As mentioned in the introduction, results of previous studies suggest that the socio-economic risk associated with birthweight accumulate over an extended period prior to childbirth (15,16,21-23). However, those studies had relatively few measures of early socioeconomic status and were mostly based on crosssectional studies with retrospective reports of early socio-economic status. The present study used longitudinal data including assessments made a decade prior to birth and at childbirth, which is unusual. Thus it was anticipated that if early socio-economic status does indeed impart significant risk for low birthweight, it would be at least as evident in the present as in the previous studies. However, no influence of early socio-economic status on birthweight was observed, after adjusting for attained socio-economic status and biomedical measures. This observation is consistent with that of Hennesy et al. (17), who also failed to observe an influence on birthweight of early socioeconomic status, after controlling for biomedical variables. In that study, grandparents' social class and smoking habits were examined for a possible relationship with the birthweight of a third generation child, but this relationship faded to insignificance when measures of biological characteristics of the mother and the child were taken into account (17). The consistency between that study and the present one and their divergence from older studies $(15,16,21,24)$, points to the possibility of important period effects.

Studies investigating the possible influence of early socio-economic conditions on low birthweight typically postulate an indirect effect of social status through maternal anthropometry (23) or nutrition (25). These are mainly based on data from women who grew up during the Great Depression in UK $(16,23)$, thus representing a social situation far different from that 30 to 40 years later, when data for the present study and the three generation study (17), were obtained. In Norway, the welfare state was well established before the majority of the mothers in the present study were born. Social and health services included an emphasis on maternal and child health, including extensive prenatal services. By the early 1970 's, a system of universal care provision had reduced prior inequalities in the prerequisites for good infant health. This truncated the range of social conditions, positively, compared to the conditions under which children were conceived and born just a few generations earlier.

Except from possible period effect, explanations of the association between current socio-economic conditions and birthweight includes: environmental (6), behavioural (26), and psycho-social factors (14), and use of prenatal medical care (27). In the present study, women with low level of education had a significantly higher risk of delivering a child with a lower birthweight. This observation is consistent with those reported by other authors $(8,28)$, and the explanatory mechanism suggested in the literature may apply to the association observed here.

The positive association between rural residency measured at the time of giving birth and subsequent birthweight observed here may be explained by maternal psychosocial stress such as job strain (29), and periods of fasting (30), which has been shown to be independent risk factors for preterm birth and low birthweight. Such risk factors may have been more prevalent among women from urban areas, compared to women from rural areas.

A weakness of the present study is the lack of data on maternal behavioural factors such as smoking, dietary habits and psychosocial conditions, all known to be related to adverse birth outcome $(1,14)$. However, in the early seventies, when the data for the present study were recorded, the prevalence of smoking among Norwegian women aged 23-44 years was approximately $10 \%$ higher among those with low education, compared to women with higher education (31). Thus we cannot exclude the possibility that smoking is an important mediating factor of the observed relationship between maternal education and low birthweight, nor that other unmeasured behavioural factors may play a mediating role.

The present results are based on measures of socioeconomic conditions for women obtained approximately 10 years before giving birth in 1960 , when the overall majority of the mothers-to-be lived at home. However, a small proportion of the women were married, divorced or a widow $(n=50)$ at that time which may have biased the results presented here. We addressed this issue by recalculating the main analysis reported here with restricted samples as described in the results excluding the proportion of women that might have lived outside the parental home and the results obtained did not differ from the analysis that included the full sample.

Some authors have raised concern about the potential problems of over-controlling in multivariable analyses of neonatal vitality including several covariates simultaneously (32). We cannot reject the possibility that effects of early socio-economic conditions are concealed by the analytic method chosen. In this regard it seems prudent to suggest that the influence of early socio-economic conditions on subsequent birthweight observed here in the adjusted multivariate analysis is mediated through current socio-economic conditions. Nevertheless, we would still argue that our analytic approach is appropriate to address the research question of interest which was to predict birthweight rather than to disentangle the causal pathways between early and current social conditions, biomedical factors and subsequent birthweight.

The starting point for the sampling of respondents was two population-based survey conducted in 1998 with a response rate of $72.7 \%$ and $66 \%$, respectively. A non-participant rate of $27.3 \%$ and $44 \%$ may have introduced selection bias. Selection bias cannot be 
estimated for the present study, but it must be assumed to exist. It is not possible to know how any selection bias may have affected the conclusions of the study.

\section{CONCLuSions}

This study contributes to the debate of the influence of early socio-economic conditions on future health by showing that early socio-economic conditions were not significantly associated with birthweight. The social conditions in which the mother's-to-be grew up under was characterised by a high level of social cohesion and universal access to pre-natal health care. Both factors may be important components in an integrated health and social policy with the objective of reducing health inequalities.

\section{ACKNOWLEDGEMENTS}

The Research Council of Norway funded this research through a grant to the first two authors. Conflicts if interest: none.

\section{REFERENCES}

1. Kramer M. Determinants of low birth weight: methodological assessment and meta-analysis. Bull World Health Organ 1987; 65: 663-737.

2. Joseph K, Kramer M. Review of the evidence on fetal and early childhood antecedents of adult chronic disease. Epidemiol Rev 1996; 18 (2): 159-174.

3. Arntzen A. Sociodemographic factors and outcome pregnancy. Doctoral dissertation, University of Oslo, 1996.

4. Kogan MD. Social causes of low birth weight. J R Soc Med 1995; 88 (11): 611-615.

5. Parker J, Schoendorf K, Kiely J. Associations between measures of socioeconomic status and low birth weight, small for gestational age, and premature delivery in the United States. Ann Epidemiol 1994; 4: 271 278.

6. Cox S, Cox T, Pryce J. Work-related reproductive health: a review. Work Stress 2000; 14 (2): 171-180.

7. Pattenden S, Dolk H, Vrijheid M. Inequalities in low birth weight: parental social class, area deprivation, and "lone mother" status. J Epidemiol Community Health 1999; 53: 355-358.

8. Kramer MS, Sèguin L, Lydon J, et al. Socio-economic disparities in pregnancy outcome: why do the poor far so poorly? Paediatr Perinat Epidemiol 2000; 14: 194-210.

9. Zeitlin J, Ancel P, Saurel-Cubizolles M, et al. Are risk factors the same for small for gestational age versus other preterm birth? Am J Obstet Gynecol 2001; 185 (1): 208-215.

10. Merritt T, Lawrence R, Naeye R. The infants of adolescent mothers. Pediatr Ann 1980; 9 (3): 100-110.

11. Wilcox MA, Smith SJ, Johnson IR, et al. The effect of social deprivation on birthweight, excluding physiological and pathological effects. Br J Obstet Gynaecol 1995; 102 (11): 918-24.

12. Page E, Villee C, Villee D. Human reproduction. Essentials of reproductive and perinatal medicine, 3 . edn. Philadelphia: W.B. Saunders Company, 1981.

13. Nordstrom-Klee B, Delaney-Black V, Covington C, et al. Growth from birth onwards of children prenatally exposed to drugs. A literature review. Neurotoxicol Teratol 2002; 24: 481-488.

14. Rutter D, Quine L. Inequalities in pregnancy outcome: A review of psychological and behavioural mediators. Soc Sci Med 1990; 30 (5): 553-568.

15. Baird D. The influence of social and economic factors on stillbirths and neonatal deaths [two parts]. J Obstet Gynaecol Br Empire 1945; 52: 217, 339.

16. Drillien $\mathrm{C}$. The social and economic factors affecting the incidence of premature birth. Premature births without complications of pregnancy. J Obstet Gynaecol Br Empire 1957; 64: 161-184.

17. Hennessy E, Alberman E. Intergenerational influence affecting birth outcome. I. Birthweight for gestational age in the children of the 1958 British Birth Cohort. Paediatr Perinat Epidemiol 1998; 12 (1): 45-60.

18. Irgens L. Births in Norway through 30 years. Bergen: Medical Birth Registry of Norway, 1997.

19. WHO. Expert Committee on Maternal and Child Health. Public health aspects of low birth weight. Technical Report Series (no. 217), World Health Organisation, 1961.

20. Vassenden K. Folke- og boligtellingene 1960, 1970 og 1980. Dokumentasjon av de sammenlignbare filene. (Census 1960, 1970, and 1980: A dokumentation of the comparable files). Kongsvinger: Statistics Norway, 1987, Report No. 87/2.

21. Emanuel I. Maternal health during childhood and later reproductive performance. Ann N Y Acad Sci 1986; 477: 27-39.

22. Emanuel I, Filakti H, Alberman E, et al. Intergenerational studies of human birth-weight from the 1958 birth cohort. 1. evidence for a multigenerational effect. Br J Obstet Gynaecol 1992; 99 (1): 67-74. 
23. Illsley R. Social class selection and class differences in relation to stillbirth and infants death. BMJ 1955; 24: 1520-1524.

24. Illsley R. Preventive medicine in the perinatal period. Proc R Soc Med Sect Epidemiol Prev Med 1966; 59: 181-184.

25. Barker D. Mothers, babies and health in later life, 2. edn. Edinburgh: Churchill Livingstone, 1998.

26. Curry M, Perrin N, Wall E. Effects of abuse on maternal complications and birth weight in adult and adolescent women. Eur J Obstet Gynecol Reproduct Biol 1998; 92: 530-534.

27. Kramer M. The epidemiology of adverse pregnancy outcomes: An overview. J Nutr 2003; 133: 1592S-1596S.

28. Arntzen A, Samuelson S, Magnus P, et al. Birth weight related to social indicators in Norway. Eur J Public Health 1994; 4: 92-97.

29. Oths K, Dunn L, Palmer N. A prospective study of psychosocial job strain and birth outcomes. Epidemiology 2001; 12 (6): 744-746.

30. Hobel C, Culhane J. Role of psychosocial and nutritional stress on poor pregnancy outcome. J Nutr $2003 ; 133$ (5): 1709S-1717S.

31. Lund K. Samfunnsskapte endringer i tobakksbruk i Norge i det 20. århundre (Societal changes in tobacco use in Norway in the 20th century) [Doctoral dissertation]. Oslo: Universitet i Oslo, 1996.

32. Kiely J. Some conceptual problems in multivariable analyses of perinatal mortality. Paediatr Perinat Epidemiol 1991; 5: 243-257. 